\title{
A STUDY OF PATTERN OF DIABETIC RETINOPATHY AND ASSOCIATED RISK FACTORS IN DIABETIC PATIENTS : A HOSPITAL BASED STUDY
}

\author{
Manoj Mehta1, Shubhra Mehta², Parul Pathak³, Amandeep Chawla ${ }^{4}$
}

\begin{abstract}
1 Professor, Department of Ophthalmology, R. D. Gardi Medical College, Ujjain, Madhya Pradesh, India.
${ }^{2}$ Associate Professor, Department of Ophthalmology, R. D. Gardi Medical College, Ujjain, Madhya Pradesh, India.

${ }^{3}$ Post Graduate Student, Department of Ophthalmology, R. D. Gardi Medical College, Ujjain, Madhya Pradesh, India.

${ }^{4}$ Post Graduate Student, Department of Ophthalmology, R. D. Gardi Medical College, Ujjain, Madhya Pradesh, India.
\end{abstract}

\begin{abstract}
BACKGROUND: Diabetes mellitus has protean manifestations in an individual and affects virtually every organ of the body. Diabetic retinopathy remains a leading cause of vision loss and blindness in people of working age- group. The present study was a hospital- based study designed to study the pattern of diabetic retinopathy and associated risk factors in diabetic individuals. MATERIAL AND METHODS: Our study was a prospective, hospital- based study of 200 cases of diabetes mellitus attending the Eye OPD at R.D. Gardi Medical College, Ujjain. All patients suffering from diabetes, irrespective of the duration of the disease, were included in the study. Each patient was subjected to a comprehensive ocular examination and the results were recorded and analyzed in detail.
\end{abstract}

RESULTS: Our study included 200 diabetic patients. Out of these 111 (55.5\%) were males and 89 (44.5\%) were females. 108 (54\%) patients were in the age group between $41-60$ years. 109 (54.5\%) patients in the study group had duration of diabetes $>5 y e a r s . ~ W e$ found that 114 (28.5\%) eyes had mild non- proliferative diabetic retinopathy (NPDR), 36 (9\%) eyes had moderate non- proliferative diabetic retinopathy, and 14 (3.5\%) eyes showed proliferative diabetic retinopathy (PDR). 61 (30.5\%) patients had raised blood pressure in the study group which suggests hypertension as a significant risk factor for diabetic retinopathy. We found that 101 (50.5\%) patients in the study group had HbA1c levels > 8gm\% and 55 (27.5\%) patients had dyslipidemia. 21 (10.5\%) patients had hemoglobin levels $<8 \mathrm{gm} \%$. The prevalence of blindness in our study group was found to be $10.3 \%$.

CONCLUSION: The results of our study show that pattern of diabetic retinopathy in an individual is directly associated with risk factors such as duration of diabetes, hypertension, poor glycemic control, dyslipidemia and anaemia.

KEYWORDS: Diabetes, Diabetic Retinopathy, Hypertension, Anaemia.

HOW TO CITE THIS ARTICLE: Manoj Mehta, Shubhra Mehta, Parul Pathak, Amandeep Chawla. "A Study of Pattern of Diabetic Retinopathy and Associated Risk Factors in Diabetic Patients : A Hospital Based Study". Journal of Evolution of Medical and Dental Sciences 2015; Vol. 4, Issue 89, November 05; Page: 15388-15391, DOI: 10.14260/jemds/2015/2193.

INTRODUCTION: Diabetes mellitus represents a syndrome with disordered metabolism and inappropriate hyperglycemia, due to either an absolute deficiency of insulin secretion, or a reduction in its biological effectiveness, or both. The number of adults with diabetes in the world is estimated to increase up to 300 million by the year $2025 .{ }^{1}$ the diabetic population in India is expected to reach 57.2 million by $2025 .{ }^{2}$ Diabetic retinopathy is a highly specific micro- vascular complication of both type 1 and type 2 diabetes mellitus. The pattern of diabetic retinopathy varies from mild non- proliferative diabetic retinopathy (NPDR) to proliferative diabetic retinopathy (PDR) depending on the type of diabetes and associated risk factors. Diabetic retinopathy remains a leading cause of vision loss and blindness in people of working age- group. It causes considerable morbidity and has a large economic impact all over the world. Patients with type 1 diabetes have a higher risk of diabetic retinopathy than those with type 2 diabetes. $^{3}$

Financial or Other, Competing Interest: None

Submission 12-10-2015, Peer Review 13-10-2015,

Acceptance 23-10-2015, Published 03-11-2015.

Corresponding Author:

Dr. Manoj Mehta,

B-4/1, Doctors Quarters,

R. D. Gardi Medical College,

Surasa, Ujjain-456006, Madhya Pradesh.

E-mail:manojvkm@yahoo.com

DOI:10.14260/jemds/2015/2193.
Duration of diabetes is the strongest predictor for development and progression of retinopathy. 4 Longer the duration of diabetes more are the chances of having diabetic retinopathy. Diabetic retinopathy affects up to $80 \%$ of all patients who have had diabetes for 10 years or more. ${ }^{5}$ Diabetic retinopathy is present in more than $77 \%$ of patients with type 2 diabetes who survive for over 20 years with the disease. 6 Poor glycemic control is associated with increased chances of having proliferative retinopathy. The risk of proliferative retinopathy increases $15 \%$ with every unit increase in HbA1c percentage. ${ }^{7}$ The other risk factors associated with worsening of diabetic retinopathy are hypertension, anaemia, hyperlipidemia, pregnancy and nephropathy. Management of diabetic retinopathy requires a proper strategy with consideration of all the associated risk factors. Research indicates that $90 \%$ of new cases of diabetic retinopathy could be reduced if there was proper vigilant treatment and monitoring of the eyes. ${ }^{8}$

Material and Method: Our study was a prospective, hospital based study of 200 cases of diabetes mellitus attending the Eye OPD at R.D. Gardi Medical College, Ujjain. The study was a prospective, hospital- based study conducted over a period of two years from September 2011 to September 2013. Approval was taken from the institutional ethics committee for the study.

Inclusion Criterion: All patients suffering from diabetes, irrespective of the duration of the disease, were included in the study. 
Exclusion Criterion: Patients with media haze obscuring visualization of fundus, and pregnant women were excluded from the study.

A written informed consent was taken from all the patients included in the study group. The preliminary data such as name, age, sex, address, occupation, socio-economic status were recorded first. Chief complaints were then recorded. A detailed past history with specific reference to the duration of diabetes, any previous ocular treatment taken was also recorded. Patients were asked about family history of diabetes. Presence of any associated risk factor like hypertension, renal disorders, anaemia, dyslipidemia was also recorded. Visual acuity was recorded first. Detailed anterior segment examination was done with help of torchlight and slit- lamp.

Iris was specifically examined for presence of rubeosis iridis. Any abnormalities of cornea and lens were also noted. Pupillary reaction was also noted. Intraocular pressure was recorded in all patients. Detailed fundus examination, by both direct and indirect ophthalmoscopy, was done in all patients after dilating the pupil. The fundus photographs were taken with TOPCON fundus camera in all the patients.. Fundus fluorescein angiography was done whenever deemed necessary.

Accordingly, the pattern of Diabetic retinopathy was recorded using the ETDRS Classification. Ultrasonography was done in all the cases. Fasting blood sugar levels, lipid profile, haemoglobin levels and glycosylated HBA1c levels were estimated in all the patients. Blood pressure was also recorded for all the patients. Proper treatment was given to all patients depending upon level of retinopathy. Follow up was done at 4 weeks and 12 weeks respectively.

RESULTS: Our study included 200 diabetic patients and out of these $111(55.5 \%)$ were males and 89 (44.5\%) were females. (Table1). Thus, our study found a male preponderance $(\mathrm{p}<0.05) .108(54 \%)$ patients were in the age group between $41-60$ years of age. 39 (19.5\%) patients were below the age of 40 years. (table2). 118 (59\%) patients were from urban areas and $82(41 \%)$ patients were from rural areas, which suggests more awareness of diabetes in urban population. $109(54.5 \%)$ patients had duration of diabetes of more than 5years in the study group whereas 91(45.5\%) patients had duration of diabetes less than 5 years of age.(figure 1 ).

The pattern of diabetic retinopathy was decided on the basis of Ophthalmoscopic findings, fundus photograph and fundus fluorescein angiographic picture. We found that 114 (28.5\%) eyes had mild non-proliferative diabetic retinopathy, 36 (9\%) eyes had moderate non-proliferative diabetic retinopathy, and 14 (3.5\%) eyes showed proliferative diabetic retinopathy (figure 2). Our study found a preponderance of mild non- proliferative diabetic retinopathy as compared to moderate non- proliferative diabetic retinopathy $(\mathrm{p}<0.05)$ in the study group. 61 $(30.5 \%)$ patients had raised blood pressure in the study group which suggests blood pressure as a significant risk factor for diabetic retinopathy. Poor glycemic control plays a very important role in development of diabetic retinopathy. We found that $101(50.5 \%)$ patients in the study group had HbA1c levels $>8 g m \%$, whereas only $22(11 \%)$ patient had HbA1c levels of $<6$ gm\%.(table 5). 55 (27.5\%) patients had dyslipidemia which suggests dyslipidemia as a strong factor for development of diabetic retinopathy.
$21(10.5 \%)$ patients had hemoglobin levels less than $8 \mathrm{gm} \%$ which suggests Anemia as an associated risk factor for the development of diabetic retinopathy. The prevalence of blindness in our study group was found to be $10.3 \%$. The results of our study show that pattern of diabetic retinopathy in an individual is directly associated with risk factors such as duration of diabetes, hypertension, poor glycemic control, dyslipidemia, anemia.

DISCUSSION: Diabetic retinopathy is one of the major tragedies of ophthalmology in our present generation and remains the leading cause of visual loss. National society (1980) has mentioned that in united states, diabetic retinopathy is the leading cause of legal blindness among people 20-74 years of age. ${ }^{9}$ In our study we also found that maximum incidence of diabetic retinopathy was observed in age group 40-60 years of age which was $56 \%$. Our study found slight preponderance of diabetes in males. 118 patients out of 200patients enrolled in the study were from urban areas which suggests increased awareness about diabetes in urban population as compared to rural population.

There are many factors such as duration of diabetes, glycemic control, awareness regarding treatment which directly influence the pattern of diabetic retinopathy in an individual. In our study we found the overall prevalence rate for any diabetic retinopathy to be $55 \%$. We found that $114(28.5 \%)$ eyes had mild non-proliferative diabetic retinopathy, 36 (9\%) eyes had moderate non-proliferative diabetic retinopathy, and 14 (3.5\%) eyes showed proliferative diabetic retinopathy. The results of our study correlated with the study of John et al who found that overall prevalence rate for any diabetic retinopathy was $52 \%$, for proliferative retinopathy was $4 \%$ and for maculopathy requiring treatment was $10 \% .{ }^{10}$

Duration of diabetes has a direct relation to the degree of diabetic retinopathy. Longer the duration of diabetes more are the chances of having retinopathy. In our study group $109(54.5 \%)$ patients had duration of diabetes of more than 5years.This result of our study correlated with study of Klein R et al who suggested in their study that the prevalence of proliferative diabetic retinopathy was $0 \%$ at 3years and increased to $25 \%$ at 15 years. ${ }^{11}$

Chamotin B et al mentioned in their study that approximately $60 \%$ of adults with type 2 diabetes have co morbid hypertension. ${ }^{12}$ in our study we also found that 61 $(30.5 \%)$ patients had raised blood pressure in the study group which suggests blood pressure as a significant risk factor for development of diabetic retinopathy.

Large fluctuations in blood sugar levels is a significant risk factor associated with worsening of diabetic retinopathy. Khandekar et al found in their study that those with HbA1c levels more than $9 \%$ had significantly higher rates of diabetic retinopathy than those with an HbA1c levels less than $9 \% .^{13}$ In our study we found that 101 (50.5\%) patients had HbA 1c levels more than $8 \mathrm{gm} . \%$ This suggests that poor glycemic control is a strong risk factor for the development of diabetic retinopathy. Davis MD et al in their study had showed an increased risk of diabetic retinopathy in diabetic patients with the haemoglobin levels of less than $12 \mathrm{~g} / \mathrm{dl} .{ }^{14}$ In our study we found that 21 $(10.5 \%)$ patients had hemoglobin levels less than $8 \mathrm{gm} \%$ which suggests Anemia as an associated risk factor for the development of diabetic retinopathy.

Rema et al 65 in their study showed an association of diabetic macular oedema in type 2 diabetic patient with increased LDL levels. ${ }^{15}$ 
In our study we found that $55(27.5 \%)$ patients had dyslipidemia. The findings of these studies suggests dyslipidemia as a strong factor for development of diabetic retinopathy. . The prevalence of blindness in our study group was found to be $10.3 \%$.

The result is comparable with the study of GUNAID et al who found in their study that the prevalence of blindness among diabetic patients was $16 \%{ }^{16}$ The findiings of our study suggest that diabetic retinopathy is a leading cause of blindness and all our efforts should be dedicated towards early detection and proper management of diabetic retinopathy.

CONCLUSION: Diabetic retinopathy causes considerable morbidity and is one of the leading causes of blindness and visual impairment. Duration of diabetes is a significant risk factor for development of diabetic retinopathy. Hypertension, poor glycemic control, anemia, dyslipidemia are other important risk factors associated with development of diabetic retinopathy Our study recommends that management of diabetic retinopathy should encompass control of associated risk factors. All efforts should be concentrated towards halting progression of diabetic retinopathy and resultant blindness.

\section{BIBLIOGRAPHY:}

1. Pal SS, Raman R, Sharma T, BMC Ophthalmology, 11: pp-2415.

2. Dowse GK, Humphrey ARG, Collins VR, Fareed D, Pelhewe W, Gareebo H, Hemraj F, Tuomilheto HR, Zimmat PZ: Prevalence and risk factors for diabetic retinopathy in multiethnic population of Mauritius. American Journal of Epidemiology, 1998; 147: 448457.

3. Narendran V, John RK, Raghuram A. Diabetic retinopathy among self-reported diabetes in Southern India: A population based assessment. Br J Opthalmol 2002; 86; 1014-8.

4. Fong DS, Lloyd A, Gardener T, King G - 'diabetic retinopathy' Diabetic Care Vol.26 supplement, Jan 2003.

5. Kertes PJ, Johnson TM. Evidence based Eye Care. ed. (2007) Philadelphia, P.A: Lippincott. Williams and Wilkins.
6. Wild S, Roglic G, Green A, Sicree R, King H: Global prevalence of diabetes: Estimates for the year 2000 and projections for 2030. Diabetes care 2004, 27: 1047- 1053.

7. Hietala K, Harjutsalo V, Forsblom C, Summmanen P. Age at onset and the risk of Proliferative Retinopathy in type 1 diabetes. Diabetes Care June; 2010; 33; 6; p1315.

8. Tapp RJ, Shaw JE; Harper (June 2003). The prevalence of and factors associated with diabetic retinopathy in Australian population. Diabetes Care 26(6): 1731 -37.

9. National society to prevent blindness. Vision problems in the US: data analysis: Definitions, data sources, detailed tables, analysis, interpretations. New York: National society to prevent blindness; 1980.

10. John MS, Bruce KM, Smith TD, Michael KB, Rosenthal ARthe prevalence of diabetic retinopathy and maculopathy and their risk factors in the non-insulin treated diabetic patients of an English town. Eye (1993), 7; 158-63.

11. Klein R, Klein BE, Moss SE, Davis MD, DeMets DL 'The Wisconsin Epidemiological Study of Diabetic RetinopathyII. Prevalence and risk of diabetic retinopathy when age at diagnosis is less than 30 years'. Arch Ophthalmol 1984; 102: 520-6.

12. Chamotin B, Poggi L, Lang T, Menard J, chevalier H, Gallios $\mathrm{H}$ et al. Prevalence, treatment and control of hypertension in the French population: data from a survey on high blood pressure in general practice, 1994. Am J hypertens 1998; 11: 759-62.

13. Khandekar $\mathrm{R}$, Lawatii $\mathrm{Al}$, and Mohammed AJ, Raisi $\mathrm{AL}$ : Diabetic retinopathy in Oman: A hospital based study. BJO; Sep 2003; 87-9.pg 1061.

14. Davis MD, Fisher MR, Gangnon RE. Risk factors for high risk Proliferative Diabetic Retinopathy and severe visual loss: Early treatment Diabetic Retinopathy Study report 18. Invest ophthalmol vis sci 1998; 39: 233-52.

15. Mohan R, Mohan V, Susheela L, Ramachandran A, Vishwanathan M. Increased LDL Cholesterol in non-insulin dependant diabetes with maculopathy. Acta Diabetol Lat 1984; 21:85-9.

16. Gunaaid AA, Bamashmus MA, Khandeker R: Diabetic retinopathy, visual impairment and ocular status among patients with diabetes mellitus in Yemen: a hospital based study. Indian J Ophthalmol;2009:293-298.

\begin{tabular}{|c|c|c|c|}
\hline $\begin{array}{c}\text { Sl. } \\
\text { No. }\end{array}$ & SEX & NUMBER OF PATIENTS & PERCENTAGE \\
\hline 1 & MALES & 111 & $55.5 \%$ \\
\hline 2 & FEMALES & 89 & $44.5 \%$ \\
\hline & TOTAL & $\mathbf{2 0 0}$ & $\mathbf{1 0 0} \%$ \\
\hline \multicolumn{2}{|c|}{ TABLE 1: DISTRIBUTION OF CASES ACCORDING TO SEX (N=200 PATIENTS) } \\
\hline
\end{tabular}

\begin{tabular}{|c|c|c|c|}
\hline $\begin{array}{c}\text { Sl. } \\
\text { No. }\end{array}$ & $\begin{array}{c}\text { AGE } \\
\text { GROUP }\end{array}$ & $\begin{array}{c}\text { NUMBER OF } \\
\text { PATIENTS }\end{array}$ & PERCENTAGE \\
\hline 1 & $10-20$ YEARS & 03 & $1.5 \%$ \\
\hline 2 & $20-30$ YEARS & 15 & $7.5 \%$ \\
\hline 3 & $30-40$ YEARS & 21 & $10.5 \%$ \\
\hline 4 & $40-50$ YEARS & 48 & $24.0 \%$ \\
\hline 5 & $50-60$ YEARS & 60 & $30.0 \%$ \\
\hline 6 & $60-70$ YEARS & 46 & $23.0 \%$ \\
\hline 7 & $>70$ YEARS & 07 & $3.5 \%$ \\
\hline \multicolumn{2}{|c|}{ TOTAL } & $\mathbf{2 0 0}$ & $\mathbf{1 0 0} \%$ \\
\hline \multicolumn{4}{|c|}{ TABLE 2: DISTRIBUTION OF CASES ACCORDING TO AGE $\mathbf{N}=\mathbf{2 0 0}$ PATIENTS) } \\
\hline
\end{tabular}




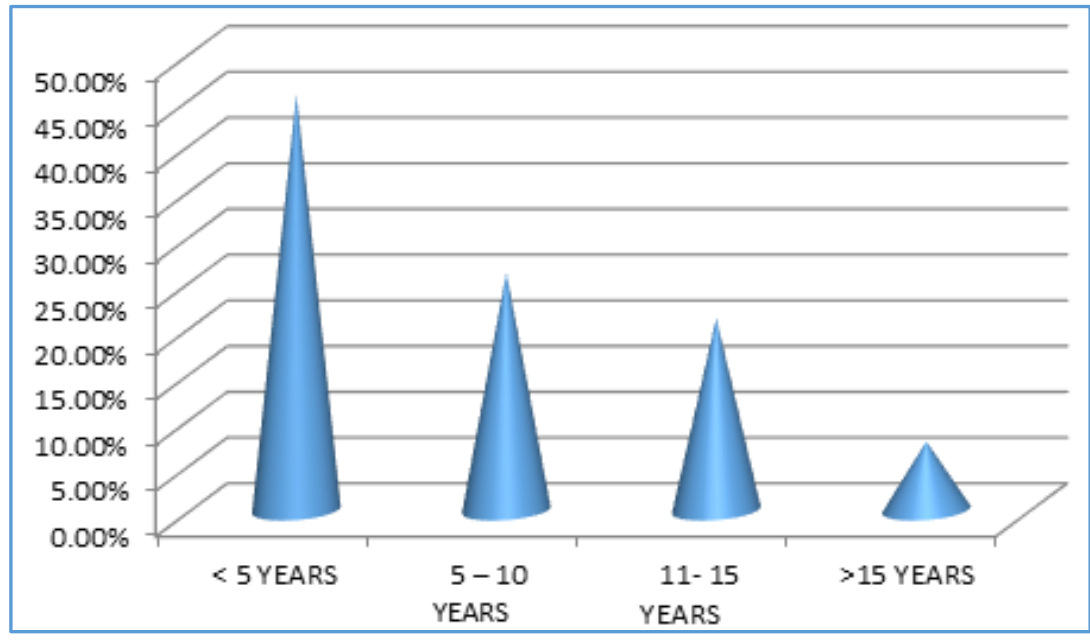

Fig. 1: Distribuition of cases according to duration of diabetes ( $\mathrm{n}=200$ patients)

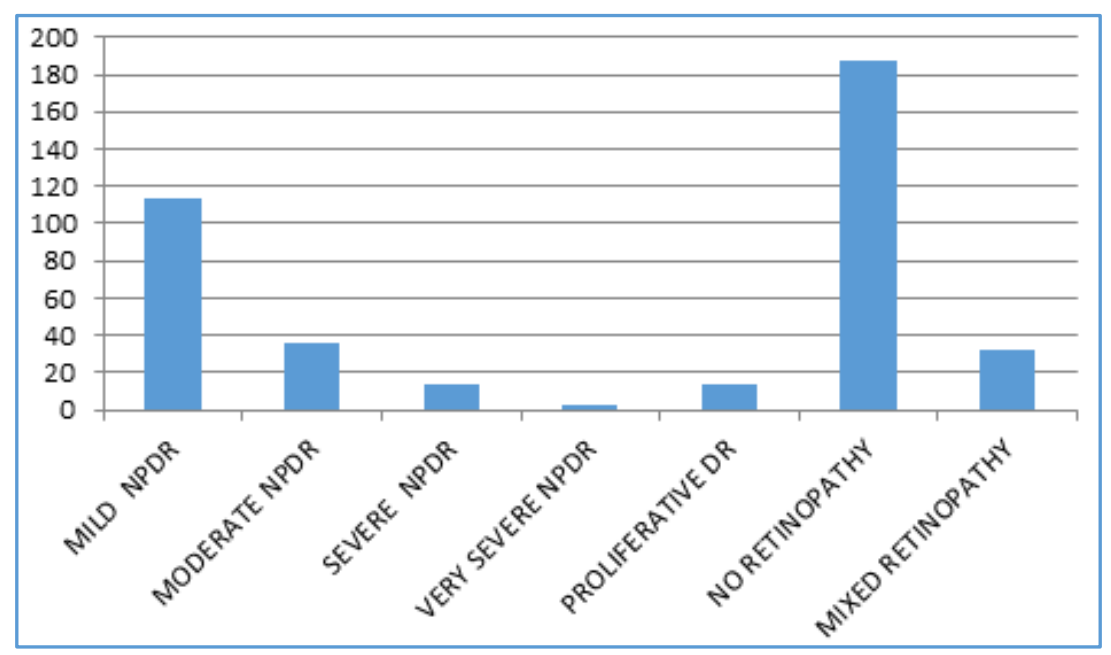

Fig. 2: Pattern of diabetic retinopathy in the study group ( $n=400$ eyes)

\begin{tabular}{|c|c|c|c|}
\hline $\begin{array}{c}\text { Sl. } \\
\text { No. }\end{array}$ & $\begin{array}{c}\text { HbAIC } \\
\text { LEVELS }\end{array}$ & $\begin{array}{c}\text { NUMBER OF } \\
\text { PATIENTS }\end{array}$ & PERCENTAGE \\
\hline 1 & $<6$ & 22 & $11.0 \%$ \\
\hline 2 & $6-8$ & 77 & $38.5 \%$ \\
\hline 3 & $8-11$ & 78 & $39.0 \%$ \\
\hline 4 & $>11$ & 23 & $11.5 \%$ \\
\hline \multicolumn{3}{|c|}{ TABLE 3: HbA1C LEVELS IN THE STUDY GROUP (N=200 PATIENTS) } \\
\hline
\end{tabular}

